\title{
Health \& Economic Burden of Traumatic Brain Injury in the Emergency Department
}

\author{
Terence S. Fu, Rowan Jing, Steven R. McFaull, Michael D. Cusimano
}

\begin{abstract}
Objective: To evaluate epidemiological patterns and lifetime costs of traumatic brain injury (TBI) identified in the emergency department (ED) within a publicly insured population in Ontario, Canada, in 2009. Methods: A nationally representative, population-based database was used to identify TBI cases presenting to Ontario EDs between April 2009 and March 2010. We calculated unit costs for medical treatment and productivity loss, and multiplied these by corresponding incidence estimates to determine the lifetime costs of identified TBI cases across age group, sex, and mechanism of injury. Results: In 2009, there were more than 133,000 ED visits for TBI in Ontario, resulting in a conservative estimate of \$945 million in lifetime costs. Lifetime cost estimates ranged from \$279 million to $\$ 1.22$ billion depending on the diagnostic criteria used to define TBI. Peak rates of TBI occurred among young children (ages 0-4 year) and the elderly (ages $85+$ years). Males experienced a 53\% greater rate of TBI and incurred two-fold higher costs compared with females. Falls, sports/bicyclist-related injuries, and motor vehicle crashes represented $47 \%, 12 \%$, and $10 \%$ of TBI presenting to ED, respectively, and accounted for a significant proportion of costs. Conclusions: This study revealed an enormous health and economic burden associated with TBI identified in the ED setting. Our findings underscore the importance of ongoing surveillance and prevention efforts targeted to vulnerable populations. More research is needed to fully appreciate the burden of TBI across a variety of health care settings.
\end{abstract}

RÉSUMÉ: Fardeau économique et fardeau de santé de lésions cérébrales traumatiques identifiées au service des urgences. Objectif: Le but de cette étude était d'évaluer le tableau épidémiologique et les coûts pendant la durée de vie de lésions cérébrales traumatiques (LCT) identifiées au service des urgences (SU) dans une population assurée par un régime publique en Ontario, au Canada, en 2009. Méthode: Une base de données populationnelles représentatives au niveau national a été utilisée pour identifier les cas de LCT s'étant présentés au SU en Ontario entre avril 2009 et mars 2010 . Nous avons calculé les coûts unitaires du traitement médical et de la perte de productivité et nous avons multiplié ces coûts par les estimés correspondants d'incidence afin de déterminer les coûts à vie des cas de LCT identifiés selon les groupes d'âge, le sexe et le mécanisme de la lésion. Résultats: En 2009, il y a eu plus de 133,000 visites au SU pour des LCT en Ontario. Ainsi, on peut estimer de façon conservatrice des coûts afférents à vie de 945 millions de dollars. Les estimés des coûts à vie allaient de 279 millions de dollars à 1,22 billion, selon les critères diagnostiques utilisés pour définir la LCT. Les jeunes enfants entre 0 et 4 ans et les vieillards de 85 ans et plus avaient les taux les plus élevés de LCT. Le taux de LCT chez les hommes était de 53\% plus élevé que celui des femmes et les coûts encourus étaient deux fois plus élevés que ceux des femmes. Les chutes, les traumatismes chez les sportifs et les cyclistes ainsi que les accidents de la route étaient respectivement la cause de $47 \%, 12 \%$ et $10 \%$ des cas de LCT se présentant au SU et représentaient une proportion importante des coûts. Conclusion: Cette étude a démontré que le fardeau de santé et le fardeau économique en lien aux LCT identifiées au SU sont énormes. Nos observations soulignent l'importance des mesures de surveillance et de prévention ciblant les populations vulnérables. De plus amples recherches sont nécessaires pour évaluer plus précisément le fardeau que constituent les LCT dans différents établissements de santé.

Keywords: Concussion, cost of illness, epidemiology, prevention, traumatic brain injury

doi:10.1017/cjn.2015.320

Can J Neurol Sci. 2016; 43: 238-247

Traumatic brain injury (TBI) is the leading cause of death and disability globally, and it is involved in nearly one-half of all trauma deaths. ${ }^{1}$ An estimated 1.7 million TBIs occur in the United States annually, resulting in 1.3 million emergency department (ED) visits and 52,000 deaths. ${ }^{2}$ Lifetime costs of medical treatment for severe TBI range from $\$ 600,000$ to $\$ 1.8$ million per case, with the value of lost productivity ten-fold higher. ${ }^{3,4}$ Additionally, survivors of TBI face long-term neuropsychiatric sequelae and their treatment requires significant health care expenditures. ${ }^{3,5-10}$ Efforts to determine the health and economic burden are important for informing public health policy, guiding appropriate allocation of resources, and targeting and evaluating prevention measures.

Examining the epidemiology of TBI treated in EDs is of particular importance, as $80 \%$ to $92 \%$ of TBIs present to the
$\mathrm{ED},{ }^{11,12}$ and recent studies show a surge in these visits. ${ }^{2,13,14}$ Yet, there are few studies examining the health care burden of TBI treated in the ED setting, and none that has calculated the costs

From the Division of Neurosurgery, Department of Surgery, St. Michael's Hospital, Toronto, Ontario, Canada, Injury Prevention Research Office, Li Ka Shing Knowledge Institute, Keenan Research Centre, University of Toronto, Toronto, Ontario, Canada (TSF, RJ, MDC); Public Health Agency of Canada, Toronto, Ontario, Canada (SRM); Dalla Lana School of Public Health, University of Toronto, Toronto, Ontario, Canada (MDC).

Presented at the Canadian Federation of Neurological Sciences 50th Annual Congress, June 9-12, 2015.

Received April 20, 2015. Final Revisions Submitted June 18, 2015.

Correspondence to: Michael D. Cusimano, Division of Neurosurgery, Department of

Surgery, Injury Prevention Research Office, Keenan Research Center, St. Michael's

Hospital, 30 Bond St., Toronto, ON, Canada, M5B 1W8. Email: injuryprevention@ smh.ca 
associated with these visits within a publicly insured population. Previous studies of TBI incidence are outdated, based on nonrepresentative populations ${ }^{15}$ or do not describe ED visits in detail. $^{16,17}$ Furthermore, to our knowledge, there is only one recent study that described the costs of TBI in a Canadian population. Chen et $\mathrm{al}^{18}$ calculated the medical costs of hospitalized TBI patients in Ontario across a variety of health care settings up to 3 years postinjury, but did not directly measure incidence or costs in the ED setting.

The present study aims to address this deficiency in the literature. We aim to describe the epidemiological patterns and lifetime costs of TBI presenting to Ontario EDs between April 2009 and March 2010 using a province-wide, population-based database. Furthermore, we identify demographic groups at risk of sustaining a TBI requiring ED treatment who represent populations for targeted injury prevention and surveillance.

\section{MeTHODS}

\section{Study Design and Population}

Incidence data were obtained from the National Ambulatory Care Resource System (NACRS) database, which collects information on patient identifiers (i.e. unique identification, health card number, postal code) and demographics (sex, birth date, education level), up to ten International Classification of Diseases, Tenth Revision (ICD-10), diagnosis codes, external causes of injury codes, ambulatory transport, and visit disposition. A recent reabstraction study compared NACRS data with the charts for 7500 ED visits at 15 Ontario hospitals in 2004-2005 and found high agreement between NACRS and chart coding. ${ }^{19}$

The study population included all ED visits between April 1, 2009, and March 31, 2010, that contained a TBI code in any diagnosis field. We defined TBI using the ICD-10 codes shown in Table 1. The Centers for Disease Control and Prevention (CDC) includes additional ICD-10 codes in their definition for TBI mortality. ${ }^{2}$ We chose a more conservative set of codes to capture TBI morbidity based on previous studies ${ }^{16,20}$ and the author's (MC) $30+$ years of clinical experience. Patients who registered but left without being seen were excluded from this study. Mechanisms of injury were defined using the CDC's External Cause of Injury Matrix ${ }^{21}$ and collapsed into several main categories: falls, struck by/against an object, motor vehicle collisions, sports- and bicyclist-related injuries, and other mechanisms. Fatal injuries occurring during transportation or after arrival to ED were identified using the "discharge disposition" variable. We used admission status as a proxy for injury severity because traditional measures (e.g. Abbreviated Injury Scale, Injury Severity Scale, Glasgow Coma Scale) were either not reported or missing in the majority of cases.

\section{Overview of Costs}

This study used a bottom-up approach to calculate lifetime costs from a societal perspective. We computed average unit costs for medical treatment and productivity loss across multiple strata (i.e. age group, sex, mechanism of injury), and multiplied these costs by corresponding incidence estimates to determine total costs. All costs were converted to 2009 Canadian dollars (CAD) using the historical currency conversion rate and Consumer Price Index for health care services in Ontario, unless otherwise

\section{Table 1: ICD-10 codes used to define TBI}

\begin{tabular}{|c|c|c|}
\hline Diagnosis & ICD-10 Code & Description \\
\hline \multirow[t]{3}{*}{ 1. Open wound of head } & S01.7 & Multiple open wound \\
\hline & S01.8 & Other part of head \\
\hline & S01.9 & Unspecified part of head \\
\hline \multirow{5}{*}{$\begin{array}{l}\text { 2. Fracture of skull and } \\
\text { facial bones }\end{array}$} & S02.0 & Skull \\
\hline & S02.1 & Base of skull \\
\hline & S02.7 & $\begin{array}{l}\text { Multiple fractures involving skull } \\
\text { and facial bones }\end{array}$ \\
\hline & S02.8 & Other skull and facial bones \\
\hline & S02.9 & Skull and facial bones, unspecified par \\
\hline 3. Intracranial injury & S06.0-S06.9 & $\begin{array}{l}\text { Includes concussion, epidural } \\
\text { hemorrhage, traumatic subdural } \\
\text { and subarachnoid hemorrhage, and } \\
\text { other/unspecified intracranial } \\
\text { injuries }\end{array}$ \\
\hline \multirow[t]{3}{*}{ 4. Crushing injury of head } & S07.1 & Skull \\
\hline & S07.8 & Other part of head \\
\hline & S07.9 & Unspecified part of head \\
\hline \multirow{3}{*}{$\begin{array}{l}\text { 5. Unspecified injury of } \\
\text { head }\end{array}$} & S09.7 & Multiple injuries of head \\
\hline & S09.8 & Other specified injuries of head \\
\hline & S09.9 & Unspecified injury of head \\
\hline \multirow{3}{*}{$\begin{array}{l}\text { 6. Injuries involving head } \\
\text { with neck }\end{array}$} & T02.0 & Fractures involving head with neck \\
\hline & T04.0 & $\begin{array}{l}\text { Crushing injuries involving head } \\
\text { with neck }\end{array}$ \\
\hline & T06.0 & $\begin{array}{l}\text { Injuries of brain and cranial nerves } \\
\text { with injuries of nerves and spinal } \\
\text { cord at neck level }\end{array}$ \\
\hline \multirow[t]{4}{*}{$\begin{array}{l}\text { 7. Sequelae of injuries of } \\
\text { head }\end{array}$} & $\mathrm{T} 90.2$ & $\begin{array}{l}\text { Sequelae of fracture of skull and facia } \\
\text { bones }\end{array}$ \\
\hline & T90.5 & Sequelae of intracranial injury \\
\hline & T90.8 & Sequelae of other injury of head \\
\hline & Т90.9 & Sequelae of unspecified injury of head \\
\hline
\end{tabular}

ICD-10 = International Classification of Diseases, Tenth Revision;

$\mathrm{TBI}=$ traumatic brain injury.

noted. ${ }^{22}$ All costs were discounted to a present value in 2009 dollars using a $3 \%$ discount rate. ${ }^{23}$ An overview of the costing approach is shown in Figure 1.

\section{Medical Costs}

We computed medical costs separately for fatal and nonfatal injuries. Costs for fatalities included ED facility costs, ${ }^{24}$ coroner/ medical examiner costs, ${ }^{25}$ and ambulatory transport $\operatorname{costs}^{26}$ (Figure 1). Cases requiring ambulatory transport were identified using the "admit via ambulance" variable. Physician fees were not included in cost estimates for fatal cases because of lack of available data. Fatalities represented only $0.1 \%$ of TBI cases; therefore, this likely does not impact cost estimates significantly.

For nonfatal injuries, we considered costs for ambulatory transport and medical treatment. Transport costs were assigned as 


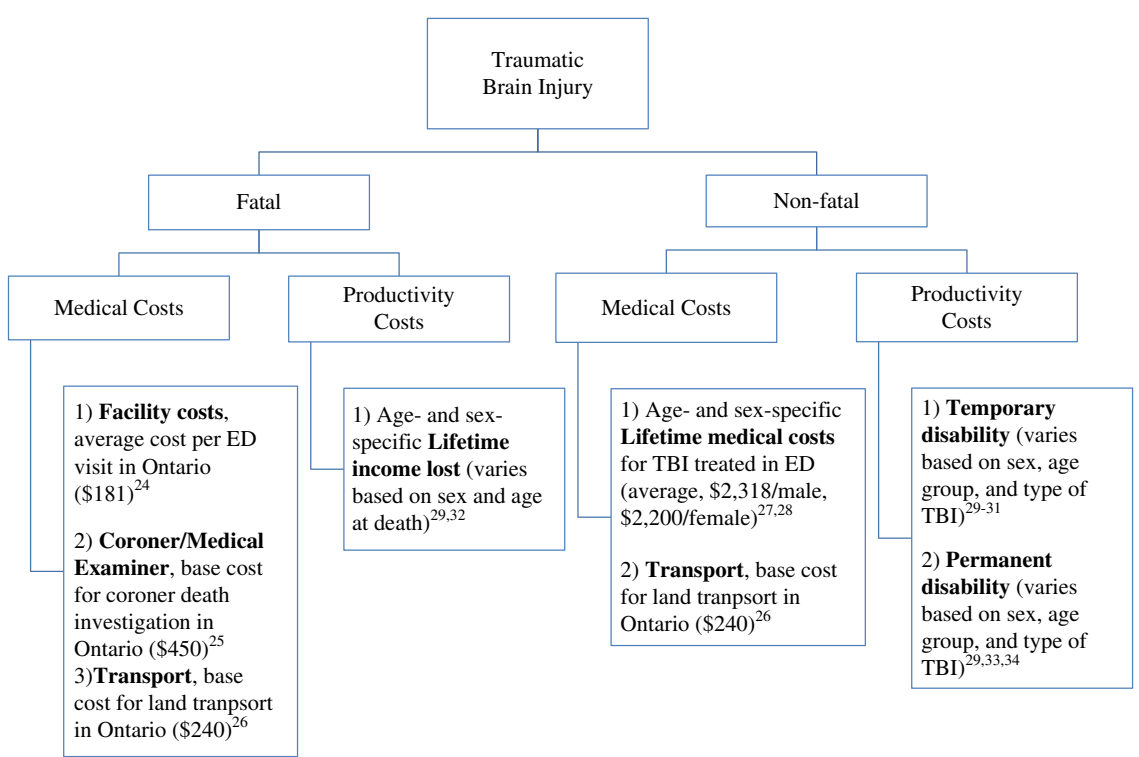

Figure 1: Overview of costing approach used to calculate medical and productivity costs for traumatic brain injury treated in Ontario emergency departments. All costs reported in 2009 Canadian dollars.

previously described. Per-patient lifetime medical costs were obtained from the CDC's Web-based Injury Statistics Query and Reporting System, ${ }^{27}$ which used nationally representative US data to calculate average cost estimates that include facility costs, physician fees, pharmacy costs, and long-term follow-up costs. We obtained average per-patient lifetime medical costs for TBI by age, sex, and nature of injury, and mapped ICD-10 codes to the corresponding nature of injury using the CDC's Injury Mortality Diagnosis Matrix. ${ }^{28}$ All costs were converted to 2009 CAD using the average quarterly currency conversion rate in 2005 and Consumer Price Index for health care services in Canada. Average lifetime costs of TBI treated in the ED were $\$ 2,318$ CAD for males (range, \$1677-\$2865) and \$2200 CAD (range, \$1618-\$3141) for females.

\section{Lost Productivity}

Productivity loss represents the value of lost potential income as a result of morbidity or death (Figure 1). We quantified productivity loss from temporary disability for the working age population (ages 15-64) by multiplying the following factors: (1) age- and sexspecific average daily income, obtained from Statistics Canada, ${ }^{29}$ (2) average workday loss from TBI, and (3) the probability that a TBI resulted in lost workdays. ${ }^{30}$ Average workday loss was obtained from a study ${ }^{31}$ that examined 1,006 TBI claims to the Workplace Safety and Insurance Board of Ontario in 2004. This study reported an average workday loss of 51.7 days and 38.1 days for male and female workers, respectively.

For fatalities, we quantified productivity loss as the net present value of lost income accrued throughout the remaining lifetime of each individual, assuming a $1 \%$ productivity growth rate and $3 \%$ discount rate. ${ }^{23,32}$ Annual income and survival data were obtained from Statistics Canada. ${ }^{29,33}$ For nonfatal cases, we calculated the cost of total permanent disability by multiplying the probability of permanent total disability by the age- and sex-specific lifetime earnings. For partial permanent disability, we multiplied lifetime earnings by the probability of partial permanent disability and an additional factor identifying the reduced earning power resulting from partial permanent disability. ${ }^{32,34,35}$

\section{Statistical Analysis}

All calculations and statistical analyses were performed using SAS 9.4 (SAS Institute, Inc., Cary, NC, USA). Rates of TBI were calculated using population data from Statistics Canada, and reported with $95 \%$ confidence intervals (CIs). A chi-square test was used to compare the incidence rate of TBI between age groups, sexes, and mechanisms of injury; Cochran's chi-squared test was used to compare the age-standardized rate between sexes. Sensitivity analysis was also used to explore the effects of modifying key study parameters, including: (1) using a more restrictive ICD-10 definition of TBI found in a previous Canadian study, ${ }^{16}$ which excluded open wounds of the head [S01(0.7-.0.9)]; (2) adopting the CDC's more inclusive ICD-10 definition of TBI mortality, ${ }^{2}$ which included ICD-10 codes corresponding to injuries of optic nerve and pathways (S04.0), open wounds involving head with neck (T01.0), and other injuries involving multiple body regions, not elsewhere classified (T06.0); (3) reducing the number of diagnosis fields examined from ten to three fields (main problem plus two other fields); and (4) varying the discount rate used to estimate productivity loss.

\section{RESULTS}

In 2009 , there were 133,952 TBI-related visits to Ontario EDs, with an overall incidence rate of 1030.6 per 100,000 (95\% CI, 1025.1-1036.1). The rate of TBI was 1250.3 per 100,000 males (95\% CI, 1241.7-1258.9) and 818.1 TBI per 100,000 females (95\% CI, 811.3-825.0). Fatalities represented only $0.1 \%$ of ED visits for TBI. Our conservative costing approach yielded annual lifetime costs of approximately \$945 million, comprising $\$ 292$ million (31\%) in medical treatment costs and $\$ 653$ million (69\%) in productivity costs. 
Table 2: Incidence rates (per 100,000) and lifetime costs of traumatic brain injury treated in Ontario EDs in 2009 by age group and gender

\begin{tabular}{|c|c|c|c|c|c|c|c|}
\hline & \multicolumn{2}{|c|}{ Fatal } & \multicolumn{2}{|c|}{ Total } & \multicolumn{3}{|c|}{ Cost (thousands) } \\
\hline & Incidence & Rate $^{*, \dagger}$ & Incidence & Rate $^{\ddagger, \S, \|}$ & Medical costs (\$) & Productivity loss (\$) & Total costs $(\$)$ \\
\hline Total & 134 & 1.0 & 133,952 & 1030.6 & 291,975 & 653,110 & 945,085 \\
\hline $0-4$ & 2 & 0.3 & 24,664 & 3494.0 & 41,512 & 55,916 & 97,429 \\
\hline $5-14$ & 6 & 0.4 & 24,048 & 1585.0 & 41,377 & 76,521 & 117,898 \\
\hline $15-24$ & 19 & 1.1 & 25,385 & 1427.0 & 56,146 & 126,871 & 183,016 \\
\hline $25-34$ & 10 & 0.6 & 12,533 & 728.5 & 31,733 & 88,223 & 119,956 \\
\hline $35-44$ & 9 & 0.5 & 10,509 & 554.4 & 25,871 & 81,290 & 107,161 \\
\hline $45-54$ & 12 & 0.6 & 10,678 & 516.7 & 25,933 & 80,169 & 106,102 \\
\hline $55-64$ & 10 & 0.7 & 7,475 & 487.4 & 19,985 & 48,931 & 68,916 \\
\hline $65-74$ & 11 & 1.2 & 5,718 & 604.8 & 15,336 & 29,563 & 44,899 \\
\hline $75-84$ & 30 & 4.9 & 7,495 & 1227.0 & 19,654 & 42,355 & 62,009 \\
\hline $85+$ & 25 & 11.2 & 5,447 & 2431.0 & 14,429 & 23,271 & 37,700 \\
\hline Male & 87 & 1.4 & 79,891 & 1250.3 & 175,134 & 466,255 & 641,388 \\
\hline $0-4$ & 2 & 0.6 & 14,544 & 4021.0 & 24,952 & 37,925 & 62,877 \\
\hline $5-14$ & 1 & 0.1 & 16,036 & 2058.0 & 27,431 & 52,576 & 80,008 \\
\hline $15-24$ & 15 & 1.7 & 17,023 & 1888.0 & 37,680 & 96,416 & 134,096 \\
\hline 25-34 & 8 & 0.9 & 8,256 & 978.3 & 21,612 & 66,849 & 88,462 \\
\hline $35-44$ & 8 & 0.8 & 6,458 & 685.8 & 16,772 & 61,661 & 78,433 \\
\hline $45-54$ & 12 & 1.2 & 6,113 & 592.1 & 16,068 & 60,209 & 76,276 \\
\hline $55-64$ & 9 & 1.2 & 3,957 & 528.2 & 10,482 & 36,232 & 46,714 \\
\hline 65-74 & 7 & 1.6 & 2,679 & 600.0 & 7,127 & 18,816 & 25,943 \\
\hline 75-84 & 17 & 6.5 & 3,092 & 1178.0 & 8,310 & 25,558 & 33,868 \\
\hline $85+$ & 8 & 11.2 & 1,733 & 2428.0 & 4,699 & 10,013 & 14,712 \\
\hline Female & 47 & 0.7 & 54,061 & 818.1 & 116,841 & 186,855 & 303,696 \\
\hline $0-4$ & 0 & 0.0 & 10,120 & 2941.0 & 16,561 & 17,991 & 34,552 \\
\hline $5-14$ & 5 & 0.7 & 8,012 & 1086.0 & 13,946 & 23,945 & 37,890 \\
\hline $15-24$ & 4 & 0.5 & 8,362 & 953.6 & 18,466 & 30,455 & 48,920 \\
\hline 25-34 & 2 & 0.2 & 4,277 & 488.0 & 10,120 & 21,374 & 31,494 \\
\hline $35-44$ & 1 & 0.1 & 4,051 & 424.8 & 9,099 & 19,629 & 28,728 \\
\hline 45-54 & 0 & 0.0 & 4,565 & 441.4 & 9,865 & 19,960 & 29,825 \\
\hline $55-64$ & 1 & 0.1 & 3,518 & 448.4 & 9,503 & 12,699 & 22,202 \\
\hline $65-74$ & 4 & 0.8 & 3,039 & 609.2 & 8,209 & 10,747 & 18,956 \\
\hline 75-84 & 13 & 3.7 & 4,403 & 1263.0 & 11,343 & 16,797 & 28,140 \\
\hline $85+$ & 17 & 11.1 & 3,714 & 2433.0 & 9,729 & 13,258 & 22,987 \\
\hline
\end{tabular}

$\mathrm{ED}=$ emergency department; $\mathrm{TBI}=$ traumatic brain injury.

*The age-standardized rates of fatal TBI for males and females were 1.5 and 0.67 per 100000 , respectively.

$\dagger$ There was a significant difference in the rate of fatal TBI between genders (Cochran's chi-square $\chi^{2}=22.350, p<0.001$ ).

$\ddagger$ The age-standardized rates of TBI for males and females were 1243.7 and 812.2 per 100000 , respectively.

$\S$ There was a significant difference in rate of total TBI between genders (Cochran's chi-square $\chi^{2}=6005.516, p<0.001$ ).

IISignificant differences were observed in the rate of TBI between genders across all age groups, except among those ages 65 - to 75 years and 85 and older.

\section{Age- and Sex-Related Incidence Patterns}

Table 2 shows the incidence of ED visits for TBI, stratified by age group and sex. Among males, 59\% of all TBI occurred in those younger than 25 years of age, with peak incidence $(21 \%)$ occurring among adolescents and young adults (ages
15-24). The highest rates of TBI for males occurred in young children ages 0 through 4 years (4021.0 per 100,000; 95\% CI, 3957.3-4085.6) and those ages 85 and older (2428.0 per 100,000; 95\% CI, 2316.1-2543.3). Among females, $49 \%$ of all TBI occurred in those younger than 25 years of age, with peak 


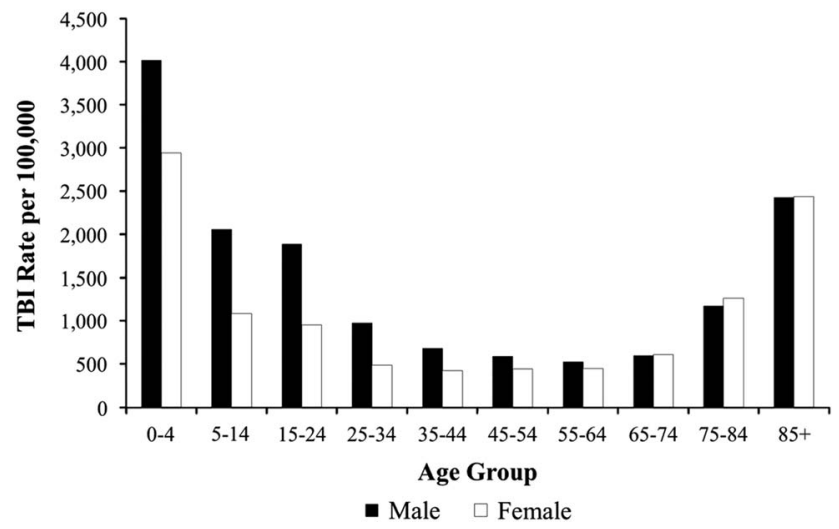

Figure 2: Age- and sex-specific rates of traumatic brain injury (TBI) presenting to Ontario emergency departments.

incidence (19\%) reported for the 0 to 4 year age group. The peak rates for females also occurred among young children ages 0 to 4 years (2941.0 per 100,000; 95\% CI, 2884.7-2997.9) and those ages 85 and older (2433.0 per 100,000; 95\% CI, 2356.3-2511.5).

The rate of TBI-related ED visits was higher for males than females across all age groups younger than 65 years of age (Figure 2). This sex difference was particularly evident within the 15 to 24 and 25 to 34 age categories, in which males were twice as likely as females to present to ED with TBI. Fatal injuries exhibited a similar sex difference because males were nearly twice as likely as females to suffer an ED visit for TBI resulting in death (Table 2). For both sexes, those ages 75 and older were most likely to suffer a fatal TBI. The 75+ age group represented $7 \%$ of the overall population, yet accounted for $41 \%$ of all fatalities resulting from TBI.

\section{Incidence Patterns by Age and Mechanism of Injury}

Table 3 shows the incidence of ED visits for TBI, stratified by sex and mechanism of injury. Falls were the most common mechanism of TBI (47\% of all injuries) and resulted in the highest rate of fatal injury (Figure 3 ). The highest rate of falls

Table 3: Incidence rates (per 100,000) and lifetime costs of TBI treated in Ontario E in 2009 by gender and mechanism of injury*

\begin{tabular}{|c|c|c|c|c|c|c|c|}
\hline & \multicolumn{2}{|c|}{ Fatal } & \multicolumn{2}{|c|}{ Total } & \multicolumn{3}{|c|}{ Cost (in thousands) } \\
\hline & Incidence $^{\dagger}$ & Rate & Incidence $^{\ddagger}$ & Rate & Medical costs (\$) & Productivity loss (\$) & Total costs $(\$)$ \\
\hline Total & 134 & 1.0 & 133,952 & 1030.6 & 291,975 & 653,110 & 945,085 \\
\hline Fall & 70 & 0.5 & 63,225 & 486.4 & 137,483 & 269,724 & 407,208 \\
\hline Struck by/against & 5 & 0.0 & 48,974 & 376.8 & 104,599 & 205,112 & 309,712 \\
\hline Motor vehicle & 48 & 0.4 & 13,512 & 104.0 & 31,187 & 130,154 & 161,342 \\
\hline Firearm & 6 & 0.0 & 93 & 0.7 & 224 & 6,985 & 7,209 \\
\hline Other & 5 & 0.0 & 8,148 & 62.7 & 18,481 & 41,134 & 59,615 \\
\hline Sports & 2 & 0.0 & 12,638 & 97.2 & 25,647 & 56,281 & 81,928 \\
\hline Bicyclist & 4 & 0.0 & 4,106 & 31.6 & 8,761 & 22,394 & 31,155 \\
\hline Male & 87 & 1.4 & 79,891 & 1250.3 & 175,134 & 466,255 & 641,388 \\
\hline Fall & 3 & 0.0 & 33,723 & 259.5 & 73,095 & 156,187 & 229,282 \\
\hline Struck by/against & 38 & 0.3 & 32,488 & 250.0 & 70,021 & 172,686 & 242,707 \\
\hline Motor vehicle & 37 & 0.3 & 8,134 & 62.6 & 19,030 & 99,568 & 118,599 \\
\hline Firearm & 5 & 0.0 & 83 & 0.6 & 202 & 5,633 & 5,835 \\
\hline Other & 4 & 0.0 & 5,463 & 42.0 & 12,785 & 32,181 & 44,965 \\
\hline Sports & 1 & 0.0 & 9,262 & 71.3 & 18,907 & 44,152 & 63,060 \\
\hline Bicyclist & 3 & 0.0 & 3,053 & 23.5 & 6,579 & 17,910 & 24,489 \\
\hline Female & 47 & 0.7 & 54,061 & 818.1 & 116,841 & 186,855 & 303,696 \\
\hline Fall & 32 & 0.2 & 30,737 & 236.5 & 67,462 & 97,038 & 164,501 \\
\hline Struck by/against & 2 & 0.0 & 15,251 & 117.3 & 31,504 & 48,925 & 80,429 \\
\hline Motor vehicle & 11 & 0.1 & 5,378 & 41.4 & 12,157 & 30,586 & 42,743 \\
\hline Firearm & 1 & 0.0 & 10 & 0.1 & 21 & 1,352 & 1,373 \\
\hline Other & 1 & 0.0 & 2,685 & 20.7 & 5,697 & 8,953 & 14,650 \\
\hline Sports & 1 & 0.0 & 3,376 & 26.0 & 6,740 & 12,129 & 18,869 \\
\hline Bicyclist & 1 & 0.0 & 1,053 & 8.1 & 2,182 & 4,484 & 6,666 \\
\hline
\end{tabular}

$\mathrm{CDC}=$ Centers for Disease Control and Prevention; $\mathrm{ED}=$ emergency department; $\mathrm{TBI}=$ traumatic brain injury.

*Mechanisms of injury were defined using the CDC's External Cause of Injury Matrix.

$†$ Fall, struck by/against, motor vehicle, firearm, and "other" mechanisms of injury add to $100 \%$ of incidence counts.

$\ddagger$ A significant difference was observed in the distribution of injury mechanisms between genders (chi-square $\chi^{2}=3740.6129, \mathrm{p}<0.0001$ ). 


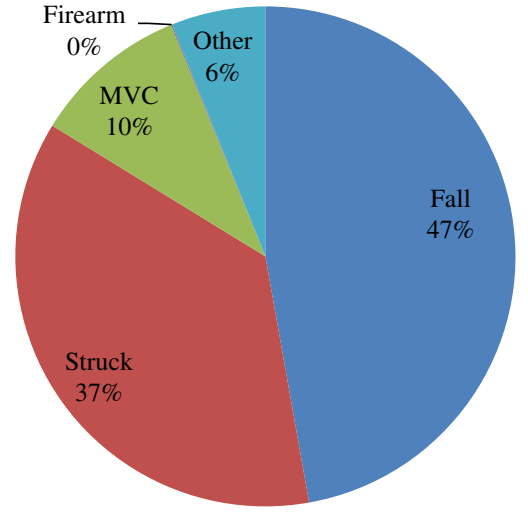

Figure 3: Incidence of traumatic brain injury identified in the emergency department by mechanism of injury.

occurred among young children (ages 0-4 years) and the elderly (age 75+ years), who together were six-fold more likely to sustain a fall-related TBI compared with other age groups. Other common causes of TBI were struck by/against injuries (37\%), motor vehicle crashes (MVCs, 10\%), and sports- and bicyclist-related injuries (combined 12\%) (Figure 3). Young children (ages $0-4$ years) were most likely to sustain TBI resulting from struck by/against injuries, whereas adolescents and young adults (ages 15-24 years) suffered the highest rate of motor vehicle injuries (results not shown). In addition, a disproportionate number of bicyclist and sports-related TBI occurred among 5 to 24 year olds. This age group was four times more likely to sustain a bicyclistrelated TBI and eight times more likely to sustain a sports-related TBI compared with other age groups.

\section{Lifetime Costs of TBI}

Total lifetime costs for TBI presenting to Ontario EDs in 2009 amounted to \$945 million; medical costs were \$292 million (31\% of total costs) and productivity costs were $\$ 653$ million (69\%; Table 3). Costs were greater for males than females across nearly all age groups, with males incurring two-fold higher costs overall (Figure 4). This finding is consistent with the fact that males suffer

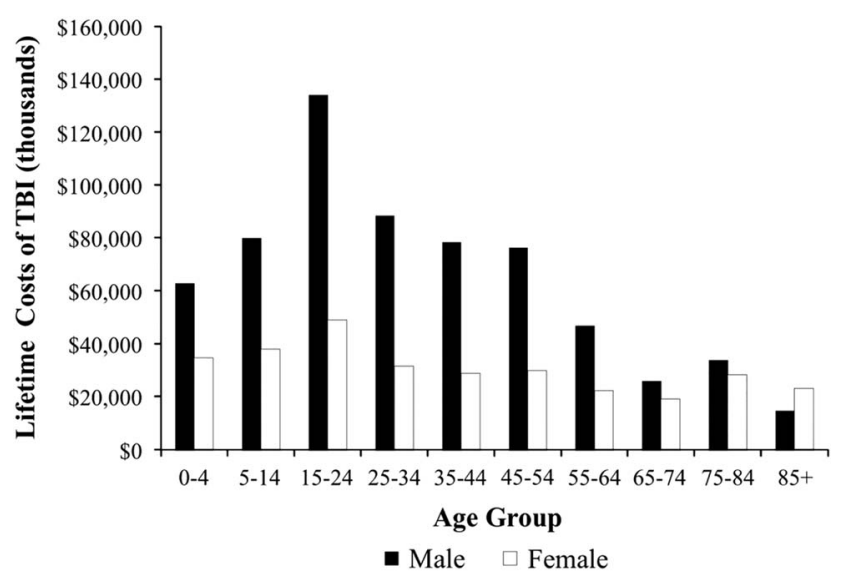

Figure 4: Estimates of lifetime costs of traumatic brain injury (TBI) treated in Ontario emergency departments by age and sex.

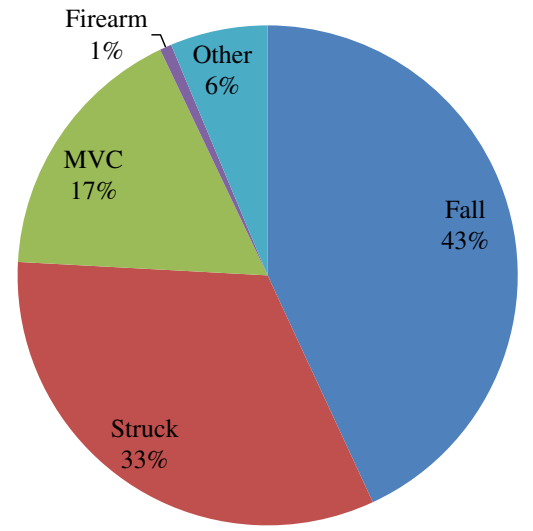

Figure 5: Lifetime costs of traumatic brain injury treated in the emergency department by mechanism of injury.

a higher rate of fatal injury and earn a higher income on average, compared with females. One exception was the 85+ year age category, in which costs were $56 \%$ higher for females than males. This cost disparity likely arises from the fact that females tend to live longer than males and accrue higher costs during elderly age. Together, falls ( $\$ 407$ million; $43 \%$ ), struck by/against (\$309 million; 33\%), and motor vehicle injuries (\$161 million; $17 \%$ ) represented $93 \%$ of lifetime costs associated with TBI (Figure 5). We noted a link between admission status (a proxy for injury severity) and lifetime costs, with admitted patients incurring $11.2 \%$ of total costs ( $\$ 106.3$ million) despite accounting for only $4.6 \%$ of TBI patients presenting to ED.

\section{Sensitivity Analysis}

Modifying key parameters had varying effects on TBI incidence and costs (Table 4). Adopting a more restrictive ICD-10 definition for TBI resulted in a significant decrease in the overall rate $(177.6$ per 100,000) and total lifetime costs ( $\$ 279$ million). In contrast, using the CDC's more inclusive ICD-10 definition, the rate of TBI increased to 1416.5 per 100,000 and lifetime costs rose to $\$ 1.22$ billion. Reducing the number of diagnosis fields from ten to three fields resulted in a slight decrease in the rate of TBI $(1023.1$ per 100,000$)$ and lifetime costs $(\$ 930$ million). Productivity costs were very sensitive to changes in the discount rate, ranging from $\$ 771$ million to $\$ 1.38$ billion using 5\% and $1 \%$ discount rates, respectively.

\section{Discussion}

Canada is among other developed countries facing the challenge of containing rising health care costs. Health care expenditures in Canada exceeded $\$ 200$ billion in 2011, and they are projected to continue to grow. ${ }^{36}$ Increasingly, policymakers have used cost-ofillness studies to guide optimal allocation of resources and identify opportunities for improving health care sustainability. ${ }^{4,37}$ The present study is the first to describe epidemiological patterns and costs of TBI presenting to the ED within a publicly insured population. We report a substantial health and economic burden associated with TBI in EDs in Ontario, Canada, and identify demographic groups at risk of sustaining TBI requiring ED treatment. 
Table 4: Results of sensitivity analysis assessing the effects of modifying key parameters on incidence and cost estimates

\begin{tabular}{l|c|c|c|c|c|c|c}
\hline & \multicolumn{2}{|c|}{ Fatal } & \multicolumn{2}{c|}{ Total } & \multicolumn{3}{c}{ Costs (in thousands) } \\
\hline Key parameters & Incidence & Rate & Incidence & Rate & Medical costs (\$) & Productivity loss (\$) & Total costs (\$) \\
\hline Baseline* & 134 & 1.03 & 133,952 & $1,030.6$ & 291,975 & 653,110 \\
\hline Restrictive ICD-10 definition of TBI $^{\dagger}$ & 79 & 0.61 & 23,087 & 177.6 & 52,180 & 226,324 & 275,085 \\
\hline CDC's ICD-10 definition of TBI mortality $^{\dagger}$ & 143 & 1.10 & 184,112 & $1,416.5$ & 402,956 & 815,536 \\
\hline Three diagnosis fields $^{\S}$ & 128 & 0.98 & 132,978 & $1,023.1$ & 289,575 & 640,061 & $1,218,492$ \\
\hline $1 \%$ Discount Raterate & 134 & 1.03 & 133,952 & $1,030.6$ & 291,975 & $1,091,926$ & $1,383,901$ \\
\hline 5\% Discount Raterate & 134 & 1.03 & 133,952 & $1,030.6$ & $\$ 291,975$ & 478,593 & 770,568 \\
\hline
\end{tabular}

$\mathrm{CDC}=$ Centers for Disease Control and Prevention; ED = emergency department; ICD-10 = International Classification of Diseases, Tenth Revision;

$\mathrm{TBI}=$ traumatic brain injury.

Abbreviations: ICD-10, International Classification of Diseases, Tenth Revision. TBI, traumatic brain injury.

*We searched all ten diagnosis fields for a TBI diagnosis, defined using the following ICD-10 codes: S01(.7-.9), S02 (.0, .1, .7-.9), S06.0-S06.9, S07

$(.1, .8, .9)$, S09(.7-.9), T02.0, T04.0, and T90(.2, .5, .8, .9).

$\dagger$ We defined TBI using a more restrictive ICD-10 definition of TBI found in a previous Canadian study: S02(.0, .1, .3, .7-.9), S04.0, S06.0-S06.9, S07

(.0-.9), T02.0, and T90(.1-.9).

\$We defined TBI using the CDC's inclusion criteria for TBI mortality: S01.0-S01.9, S02(.0, .1, .3, .7-.9), S04.0, S06.0-S06.9, S07(.0, .1, .8, .9), S09(.7-.9), T01.0, T02.0, T04.0, T06.0, and T90(.1, .2, .4, .5, .8, .9).

§We searched for a TBI diagnosis in three diagnosis fields (i.e. main diagnosis plus two other diagnosis fields).

\section{Health and Economic Burden of TBI: Comparison to the Literature}

The TBI rates reported in the present study are significantly higher than those described in previous Canadian ${ }^{15,16}$ and US studies. ${ }^{13,38,39}$ Greater rates could indicate an increase in injuries over time; one US study found that ED visits for TBI increased at an eight-fold higher rate compared with total ED visits from 2006 to $2010 .{ }^{13}$ Discrepancies could also be explained by differences in data sources, methods of data collection, geographical location, and ICD-code inclusion criteria. For instance, on sensitivity analysis, adopting ICD-10 definitions of varying inclusiveness resulted in a wide range of estimates for TBI rates (177.6-1416.5 per 100,000) and lifetime costs ( $\$ 279$ million to $\$ 1.22$ billion). The true health and economic burden of TBI likely falls within these ranges. Our study highlights the need for a standardized ICD-10 definition of TBI morbidity as well as studies based on more recent data to generate meaningful comparisons across studies. ${ }^{2,15-17,38,39}$

Our study also shows that TBIs treated in the ED setting represent a larger economic burden than suggested by previous Canadian studies. Chen et $\mathrm{al}^{18}$ estimated the 3-year medical costs for hospitalized TBI patients in Ontario across a continuum of health care services, including ED care, acute inpatient care, inpatient rehabilitation, and complex continuing care. They calculated that medical costs for TBI treated in various health care settings (including the ED) were $\$ 446$ million (2009 CAD) in the first 3 years postinjury. In contrast, the present study estimated annual medical costs of $\$ 292$ million for TBI treated in the ED alone. This discrepancy in cost estimates can be explained by differences in study period, data sources, TBI inclusion criteria, and costing methodology. For instance, Chen et $\mathrm{al}^{18}$ underestimated ED costs by assuming a single ED visit per TBI inpatient valued at only $\$ 187 \mathrm{CAD}$. In addition, Chen et $\mathrm{al}^{18} \mathrm{did}$ not examine the lifetime costs of TBI, which have been shown to be substantial. ${ }^{3,4,27}$
In a different report, the Canadian Institute of Health Information (CIHI) found that the direct costs of head injury in Canada including all hospital, physician, and drug costs were $\$ 183$ million (2009 CAD) in $2000 .{ }^{17}$ As a crude comparison, we applied age- and sex-specific incidence-to-population ratios to our provincial estimates to obtain national costs of medical treatment of \$754 million-more than four-fold greater than the CIHI estimate. Discrepancies can be explained by the same previously mentioned differences in study design and that CIHI estimate did not consider long-term costs. Additionally, higher medical costs could indicate an increase in the rate and/or severity of TBI over the past decade, a well-reported trend in the literature. ${ }^{2,13,14,40}$ Studies have also demonstrated a clear link between TBI severity and costs. ${ }^{7,8,10}$ In our study, we used admission status as a proxy for injury severity and found that admitted patients incurred a disproportionate amount of total costs compared with nonadmitted patients.

\section{Vulnerable TBI Populations and Policy Implications}

Our study highlighted the importance of fall prevention efforts targeted to the youngest and oldest segments of the population (ages 0-4 and 75+), who remain at greatest risk of suffering a fall-related TBI. ${ }^{2,17,38,39}$ Fall prevention strategies targeting young children include improved helmet laws and child safety equipment, safer sports practices, and increased TBI awareness. ${ }^{41}$ In addition, multifaceted programs incorporating patient education, environmental safety modification, drug regimen reviews, and other interventions have been shown to be effective in reducing falls among the elderly. ${ }^{42,43}$

This study also found a high incidence of TBIs caused by MVCs. In our study, peak rates of MVCs occurred among adolescents and young adults (ages 15-24), a finding that is well-supported in the literature. ${ }^{2,13,44-46}$ Furthermore, although MVCs accounted for only $10 \%$ of TBIs, they encompassed more 
than $17 \%$ of total lifetime costs. This disproportionately large cost reflects the long-term debilitating sequelae of MVCs and the tendency to afflict younger age groups, resulting in substantial lifetime medical and productivity costs. ${ }^{4}$ Our findings emphasize the need for prevention efforts targeted to these vulnerable groups. In Ontario, a graduated driver licensing program was introduced in 1994 requiring new drivers to advance through two stages of licensing. Additional young driver restrictions have been added over time, including a recent 2009 law mandating a zero blood alcohol concentration for drivers younger than age 22 years. Previous studies have demonstrated the effectiveness of graduated driver licensing programs and impaired driving laws at reducing MVC rates, particularly among young adults. ${ }^{4,46}$

In addition, we reported a significant incidence of sports- and bicyclist-related injuries (12\% of TBI) affecting primarily children and young adults (ages 5-24), a finding supported in the literature. $^{41,43,47}$ Other studies report that sports-related injures compose up to $19 \%$ to $20 \%$ of TBI, and recent reports show that rates have been increasing over time, particularly among this age group. ${ }^{41,47,48}$ The significant and rising rate of sports-related TBI warrants the need for enhanced surveillance and targeted prevention efforts among these age groups. Previous research has highlighted several successful interventions, including education and awareness campaigns, reorganization sports sponsorship and governance, enforcement of sports safety rules and return-to-play guidelines, and development of resources to assist clinicians in the diagnosis and management of TBI. ${ }^{43,49,50}$

\section{Study Limitations and Future Directions}

The present study is subject to certain limitations. Incidence is based on the NACRS database, which does not account for those treated in physician offices or fatalities occurring outside of the ED. Incidence data are also subject to potential miscoding, particularly given the large number of ED visits (47\% of identified cases) coded as unspecified head injuries (S09.9), which may include visits for other TBI or non-TBI diagnoses. Additionally, this database does not capture TBI patients who did not seek ED treatment. TBI has been described as the "silent epidemic" because neuropsychiatric sequelae such as cognitive dysfunction, depression, and anxiety are not immediately apparent. Our study likely underestimates the true incidence of TBI, because reports show that up to $39 \%$ of these injuries remain undiagnosed. ${ }^{51}$ Furthermore, TBI is likely underdiagnosed in the ED setting, because observed signs of neurologic and neuropsychiatric sequelae cannot be used to make the diagnosis of TBI in the absence of loss of consciousness (LOC) or altered consciousness. ${ }^{6}$ However, studies have shown that LOC is an unreliable predictor of TBI diagnosis, with the presence of LOC and TBI diagnosis coexisting at varying frequencies ranging from $32 \%$ to $50 \%$. $^{6,51,52}$

Our approach for estimating costs also requires additional caveats. There is no single source that exists for estimating costs; consequently, we used the best available data taken from a myriad of sources, recognizing that each is subject to limitations. Because of the paucity of Canadian literature and data on the costs of TBI treated in ED, lifetime medical costs were adapted from large nationally representative US data under the assumption that the epidemiology and treatment patterns for TBI are relatively uniform in North America. However, differences in health care delivery, access, and reimbursement could limit the applicability of these data. The cost estimates reported in this study should be interpreted in the context of these limitations. Future studies with better data will improve upon the precision of our cost estimates. In addition, although we used admission status as a proxy for injury severity, we were unable to stratify costs by common measures of injury severity due to underreporting and lack of these data. More work is needed to elucidate the link between costs and injury severity in the publicly insured ED setting.

This study used a conservative approach to define TBI and designate unit costs. We did not assess quality of life loss, productivity losses borne by family members, or intangible costs of disease such as grief and pain. These costs, although difficult to quantify, are likely to be substantial, with one study reporting annual quality of life costs of $\$ 129$ billion for TBI. ${ }^{9}$ Furthermore, we did not include costs associated with other well-known consequences of TBI, including suicide, alcohol and drug abuse, and mental health issues. ${ }^{4}$ Therefore, we believe that the costs presented in this study significantly underestimate the true economic burden of TBI in Ontario.

Despite these limitations, our study provides the best available estimates of TBI incidence and costs in the ED setting within a publicly insured population, and presents unequivocal evidence of the substantial health and economic burden associated with these injuries. Future research should focus on the direct measurement of per-patient ED costs using primary or secondary data from a publicly insured population. Additionally, cost analysis could be extended to examine the relative impact of factors influencing TBI incidence and costs, such as comorbidities, ICD-10 diagnosis, or markers of TBI severity. Finally, studies could expand the geographical scope of this study and extend cost estimates to include more diverse health care settings such as hospitals and physician offices.

\section{CONCLUSIONS}

This study reported a substantial health and economic burden associated with TBI in the ED setting. We conducted our analyses using a nationally representative, population-based database which is mandatory for all EDs in Ontario. In 2009, there were more than 133,000 TBI-related ED visits in Ontario, resulting in total lifetime costs of $\$ 945$ million. Lifetime costs were sensitive to changes in the ICD-10 definition for TBI, with estimates ranging from $\$ 279$ million to 1.22 billion using definitions of varying inclusiveness. We identified several high-risk populations that would benefit from targeted injury prevention measures, with an emphasis on fall prevention among the elderly, MVC prevention among young adults, and sports-/bicyclist-related TBI prevention among youth. Efforts to evaluate the economic burden of TBI are important because of its prevalence and potential for long-term disability. This study can serve as an initial evaluation and case report to guide the assessment of economic burden in other similar publicly insured populations.

\section{ACKNOWLEDGMENTS}

The authors thank Stanley Zhang for his contributions and administrative support, and Jane Topolovec-Vranic, Holly Hedegaard, and Bing Li for their input in methodology discussions. We also extend our thanks to Bruce Lawrence and Ted Miller for sharing with us their wisdom and data. 
This research was supported by the Canadian Institutes of Health Research Strategic Team Grant in Applied Injury Research \#TIR-103946 and the Ontario Neurotrauma Foundation.

\section{Statement of Authorship}

All authors contributed extensively to the work presented in this paper. TSF, RJ, and MDC jointly conceived the study design; SRM and RJ collected and analyzed the data; TSF interpreted the results and prepared the manuscript under supervision from MDC; RJ and SRM provided technical support and conceptual advice; and all authors discussed the results and implications and edited the manuscript.

\section{Disclosures}

The authors have nothing to disclose.

\section{REFERENCES}

1. World Health Organization [Internet]. Neurological Disorders: Public Health Challenges; 2006. Available from: http://www.who.int/ mental_health/neurology/neurodiso/en/.

2. US Department of Health and Human Services, Centers for Disease Control and Prevention. Traumatic Brain Injury in the United States: Emergency Department Visits, Hospitalizations and Deaths 2002-2006; 2010. Available from: http://www.cdc.gov/ TraumaticBrainInjury/tbi_ed.html.

3. Consensus conference. Rehabilitation of persons with traumatic brain injury. NIH Consensus Development Panel on Rehabilitation of Persons With Traumatic Brain Injury. JAMA. 1999;282:974-83.

4. Finkelstein ES CP, Miller TR. The incidence and economic burden of injuries in the United States. New York, NY: Oxford University Press; 2006.

5. Hoofien D, Gilboa A, Vakil E, Donovick PJ. Traumatic brain injury (TBI) 10-20 years later: a comprehensive outcome study of psychiatric symptomatology, cognitive abilities and psychosocial functioning. Brain Inj. 2001;15:189-209.

6. Faul M, Coronado V. Epidemiology of traumatic brain injury. Handbook Clin Neurol. 2015;127:3-13.

7. Vangel SJ, Jr., Rapport LJ, Hanks RA, Black KL. Long-term medical care utilization and costs among traumatic brain injury survivors. Am J Phys Med Rehab. 2005;84:153-60.

8. Rockhill CM, Jaffe K, Zhou C, Fan MY, Katon W, Fann JR. Health care costs associated with traumatic brain injury and psychiatric illness in adults. J Neurotrauma. 2012;29:1038-46.

9. Miller TR ZE, Hendrie D. Cost of Traumatic Brain Injury and Return on Helmet Investment in the United States. In: Jallo J LC, ed. Neurotrauma and critical care. New York: Thieme Medical Publishers, Inc.; 2009:445-58.

10. McGarry LJ, Thompson D, Millham FH, et al. Outcomes and costs of acute treatment of traumatic brain injury. $J$ Trauma. 2002; 53:1152-9.

11. Rutland-BrownW LJ, Thomas KE, Lily YL. Incidence of traumatic brain injury in the United States, 2003. J Head Trauma Rehab. 2006;21:544-8.

12. Selassie AW, McCarthy ML, Pickelsimer EE. The influence of insurance, race, and gender on emergency department disposition. Acad Emerg Med. 2003;10:1260-70.

13. Marin JR, Weaver MD, Yealy DM, Mannix RC. Trends in visits for traumatic brain injury to emergency departments in the United States. JAMA. 2014;311:1917-9.

14. Coronado VG, McGuire LC, Sarmiento K, et al. Trends in traumatic brain injury in the U.S. and the public health response: 19952009. J Safety Res. 2012;43:299-307.

15. Pickett W, Ardern C, Brison RJ. A population-based study of potential brain injuries requiring emergency care. CMAJ. 2001;165:288-92.
16. Colantonio A, Saverino C, Zagorski B, et al. Hospitalizations and emergency department visits for TBI in Ontario. Can J Neurol Sci. 2010;37:783-90.

17. Canadian Institute of Health Information (CIHI) [Internet]. The burden of neurological diseases, disorders and injuries in Canada: head injury. Ottawa; 2007. Available from: https://secure.cihi.ca/ free_products/BND_e.pdf.

18. Chen A, Bushmeneva K, Zagorski B, Colantonio A, Parsons D, Wodchis WP. Direct cost associated with acquired brain injury in Ontario. BMC Neurol. 2012;12:76.

19. Canadian Institute of Health Information (CIHI) [Internet]. Data Quality Study of Emergency Department Visits for 2004-2005: Volume II of IV - Main Study Findings. Ottawa, ON; 2008. Available from: https://secure.cihi.ca/free_products/vol1_nacrs_ executive_summary_nov2_2007.pdf.

20. Thurman D, Kraus J, Romer C. Standards for surveillance of neurotrauma. Geneva, Switzerland: World Health Organization; 1995.

21. Centers for Disease Control and Prevention (CDC). [Internet]. External Cause of Injury Mortality Matrix for ICD-10 2010. Available from: http://www.cdc.gov/nchs/data/ice/icd10_ transcode.pdf.

22. Statistics Canada. Table 326-0021 - Consumer Price Index (CPI), 2011 basket: CANSIM; 2014

23. Haddix A, Teutsch SM, Corso PS. Prevention effectiveness, a guide to decision analysis and economic evaluation, 2nd ed. New York: Oxford University Press; 2003.

24. Ministry of Health and Long-Term Care Health Data Branch. Data Quality Review: Emergency Total Expenses \& Visits for Reporting Period 2009/2010YE.

25. Mahyr C. Costs associated with death investigations: Office of the Chief Coroner. Ontario Forensic Pathology Service; 2014.

26. Ministry of Health and Long-Term Care Health Data Branch. Ambulance Services Billing. Available from: http://www.health. gov.on.ca/english/public\%5Cprogram/ehs/land/service_qa.html.

27. Centers for Disease Control and Prevention [Internet]. Web-based Injury Statistics Query and Reporting System (WISQARS). Available from: http://www.cdc.gov/injury/wisqars/index.html.

28. Fingerhut LA, Warner M. The ICD-10 injury mortality diagnosis matrix. Inj Prev. 2006;12:24-9.

29. Statistics Canada. Table 202-0407: Income of individuals, by sex, age group and income source, 2011 constant dollars, annual: CANSIM; 2013.

30. Lawrence BA MT, Jensen AF, Fisher DA, Zamula WW. Estimating the costs of non-fatal consumer product injuries in the United States. Inj Contr Safety Prom. 2000;7:97-113.

31. Colantonio A, Mroczek D, Patel J, Lewko J, Fergenbaum J, Brison R. Examining occupational traumatic brain injury in Ontario. Can J Public Health. 2010;101(Suppl 1):S58-62.

32. Lawrence BA, Bhattacharya S, Zaloshnja E, Jones P, Miller TR, Corso PS, et al. Medical and Work Loss Cost Estimation Methods for the WISQARS Cost of Injury Module. Calverton, MD: PIRE; 2011.

33. Statistics Canada [Internet]. Life Tables, Canada, Provinces and Territories, 2009 to 2011 (84-537-X; No. 005). Ottawa, ON: Statistics Canada; 2013. Available from: http://www5. statcan.gc.ca/olc-cel/olc.action?objId=84-537-X\&objType $=2 \&$ lang $=$ en\&limit $=0$

34. Berkowitz M, Burton JF. Permanent disability benefits in workers' compensation. Kalamazoo, MI; 1987. Available from: http:// research.upjohn.org/up_press/101/.

35. Miller TR DJ, Rossman SB. Databook on Nonfatal Injury: Incidence, Costs, and Consequences: Incidence, Costs, and Consequences. Washington, DC: The Urban Institute Press; 1995.

36. Canadian Institute of Health Information (CIHI). National Health Expenditure Trends 1975 to 2013. Ottawa, ON, 2011.

37. Khan S, Khan A, Feyz M. Decreased Length of stay, cost savings and descriptive findings of enhanced patient care resulting from and integrated traumatic brain injury programme. Brain Inj. 2002; 16:537-54.

38. Guerrero JL, Thurman DJ, Sniezek JE. Emergency department visits associated with traumatic brain injury: United States, 1995-1996. Brain Inj. 2000;14:181-6. 
39. Jager TE, Weiss HB, Coben JH, Pepe PE. Traumatic brain injuries evaluated in U.S. emergency departments, 1992-1994. Acad Emerg Med. 2000;7:134-40.

40. Canadian Institute of Health Information (CIHI) [Internet]. Head Injuries in Canada: A Decade of Change (1994-1995 to 20032004). Ottawa; 2006. Available from: https://secure.cihi.ca/ free_products/ntr_head_injuries_2006_e.pdf.

41. Hanson HR, Pomerantz WJ, Gittelman M. ED utilization trends in sports-related traumatic brain injury. Pediatrics. 2013;132: e859-64.

42. Cusimano MD, Kwok J, Spadafora K. Effectiveness of multifaceted fall-prevention programs for the elderly in residential care. Inj Prev. 2008;14:113-22.

43. Cusimano MD, Cho N, Amin K, Shirazi M, McFaull SR, Do MT, et al. Mechanisms of team-sport-related brain injuries in children 5 to 19 years old: opportunities for prevention. PLoS One. 2013;8:e58868.

44. Fu TS, Jing R, McFaull SR, Cusimano MD. Recent trends in hospitalization and in-hospital mortality associated with traumatic brain injury in Canada: a nationwide, population-based study. J Trauma Acute Care Surg. 2015;79(Suppl 1):449-55.

45. Mayhew D, Simpson HM, Singhal D. Best practices for graduated driver licensing in Canada. Ottawa: Traffic Injury Research Foundation; 2005.
46. Simniceanu A, Richmond SA, Snowdon A, Hussein A, Boase P, Howard A. Child restraint use in Canadian provinces with and without legislation in 2010. Traff Inj Prev. 2014;15:734-9.

47. Coronado VG, Haileyesus T, Cheng TA, Bell JM, Haarbauer-Krupa J, Lionbarger MR, et al. Trends in sports- and recreation-related traumatic brain injuries treated in US emergency departments: the National Electronic Injury Surveillance System-All Injury Program (NEISS-AIP) 2001-2012. J Head Trauma Rehab. 2015; 30:185-97.

48. Selassie AW, Wilson DA, Pickelsimer EE, Voronca DC, Williams NR, Edwards JC. Incidence of sport-related traumatic brain injury and risk factors of severity: a population-based epidemiologic study. Ann Epidemiol. 2013;23:750-6.

49. Donaldson L, Asbridge M, Cusimano MD. Bodychecking rules and concussion in elite hockey. PLoS One. 2013;8:e69122.

50. Marchie A, Cusimano MD. Bodychecking and concussions in ice hockey: should our youth pay the price? CMAJ. 2003; 169:124-8.

51. Boswell JE, McErlean M, Verdile VP. Prevalence of traumatic brain injury in an ED population. Am J Emerg Med. 2002;20:177-80.

52. Dutton RP, Prior K, Cohen R, Wade C, Sewell J, Fouche Y, et al. Diagnosing mild traumatic brain injury: where are we now? J Trauma. 2011;70:554-9. 